\title{
A RANDOMIZED DOUBLE-BLIND STUDY OF THE EFFECT OF TRIIODOTHYRONINE ON CARDIAC FUNCTION AND MORBIDITY AFTER CORONARY BYPASS SURGERY
}

Samantha L. Mullis-Jansson, MD

Michael Argenziano, MD ${ }^{\mathrm{b}}$

Steven Corwin, $\mathrm{MD}^{\mathrm{c}}$

Shunichi Homma, $\mathrm{MD}^{\mathrm{c}}$

Alan D. Weinberg, MS ${ }^{\mathrm{b}}$

Mat Williams, MD $^{\mathrm{b}}$

Eric A. Rose, $M^{b}$

Craig R. Smith, MD
Background: Although triiodothyronine deficiency has been described after cardiopulmonary bypass, data supporting its use have been conflicting. A double-blind, randomized, placebo-controlled study was undertaken to further define the effect of triiodothyronine on hemodynamics and outcome after coronary artery bypass grafting. Methods: A total of 170 patients undergoing elective coronary artery bypass grafting were enrolled and completed the study from November 1996 through March 1998. On removal of the aortic crossclamp, patients were randomized to receive either intravenous triiodothyronine $(0.4$ $\mu \mathrm{g} / \mathrm{kg}$ bolus plus $0.1 \mu \mathrm{g} / \mathrm{kg}$ infusion administered over a 6-hour period, $n=81)$ or placebo $(n=89)$. Outcome variables included hemodynamic profile and inotropic drug/pressor requirements at several time points (mean \pm standard error of the mean), perioperative morbidity (arrhythmia/ischemia/infarction), and mortality. Results: Despite similar baseline characteristics, patients randomized to triiodothyronine had a higher cardiac index and lower inotropic requirements after the operation. Subjects receiving triiodothyronine demonstrated a significantly lower incidence of postoperative myocardial ischemia $(4 \%$ vs $18 \%, P=.007)$ and pacemaker dependence $(14 \%$ vs $25 \%, P=.013)$. Seven patients in the placebo group required postoperative mechanical assistance (intraaortic balloon pump, $n=4$; left ventricular assist device, $n=3$ ), compared with none in the triiodothyronine group $(P=.01)$. There were 2 deaths in the placebo group and no deaths in the triiodothyronine group. Conclusions: Parenteral triiodothyronine given after crossclamp removal during elective coronary artery bypass grafting significantly improved postoperative ventricular function, reduced the need for treatment with inotropic agents and mechanical devices, and decreased the incidence of myocardial ischemia. The incidence of atrial fibrillation was slightly decreased, and the need for postoperative pacemaker support was reduced. (J Thorac Cardiovasc Surg 1999;117:1128-35)
$\mathrm{T}$ hyroid hormone has long been known to exert profound effects on the cardiovascular system. The physiologic effects of thyroid hormone result from the

From the Departments of Anesthesiology, ${ }^{\text {a }}$ Surgery, ${ }^{\mathrm{b}}$ and Medicine, ${ }^{\mathrm{c}}$ Columbia University College of Physicians and Surgeons, New York, NY.

Read at the Seventy-eighth Annual Meeting of The American Association for Thoracic Surgery, Boston, Mass, May 3-6, 1998.

Received for publication May 8, 1998; revisions requested July 8, 1998; revisions received Feb 18, 1999; accepted for publication Feb 19, 1999

Address for reprints: Samantha L. Mullis-Jansson, MD, 177 Fort Washington Ave, New York, NY 10032.

Copyright @ 1999 by Mosby, Inc.

$0022-5223 / 99 \$ 8.00+0 \quad \mathbf{1 2 / 6 / 9 8 0 6 9}$ actions of both triiodothyronine $\left(\mathrm{T}_{3}\right)$ and tetraiodothyronine $\left(\mathrm{T}_{4}\right)$ on a variety of organ systems. These include a decrease in peripheral vascular resistance and positive chronotropic and inotropic effects. ${ }^{1-5}$

Several studies evaluating the impact of $\mathrm{T}_{3}$ administration on low output states after cardiopulmonary bypass have yielded conflicting data. ${ }^{6-9}$ The purpose of our study was to re-examine the impact of intravenous $\mathrm{T}_{3}$ administration on hemodynamic variables, inotropic support requirements, and morbidity/mortality after coronary artery bypass grafting $(\mathrm{CABG})$.

\section{Methods}

After institutional review board approval and informed written consent, patients undergoing $\mathrm{CABG}$ at Columbia- 
Presbyterian Medical Center were enrolled in a prospective, double-blind, placebo-controlled trial over a 2-year period. A total of 177 patients undergoing elective CABG were enrolled from September 1996 through March 1998. The nature of the operation between the 2 groups was as follows: left internal thoracic artery, $\mathrm{n}=145\left(69 \mathrm{~T}_{3}\right.$ and 76 placebo); right internal thoracic artery, $\mathrm{n}=1$ (placebo); bilateral internal thoracic arteries, $\mathrm{n}=20\left(10 \mathrm{~T}_{3}\right.$ and 10 placebo $)$; and no internal thoracic artery usage, $\mathrm{n}=6\left(4 \mathrm{~T}_{3}\right.$ and 2 placebo). The number of grafts per patient breaks down as follows: 1 vessel, 3 patients; 2 vessels, 32 patients; 3 vessels, 69 patients; 4 vessels, 49 patients; 5 vessels, 19 patients; and 6 vessels, 1 patient. Exclusionary criteria included valvular surgery, history of thyroid disease or thyroid replacement therapy, evolving myocardial infarction, age greater than 85 years, preoperative insertion of an intra-aortic balloon pump, and emergency operation. Subjects were randomly assigned to 1 of 2 groups. The placebo and $\mathrm{T}_{3}$ groups were equally divided among the surgeons participating in the study. Patients randomized to the $\mathrm{T}_{3}$ group received $\mathrm{T}_{3}$ intravenously at the time of aortic crossclamp removal $(1 \mu \mathrm{g} / \mathrm{kg}$ bolus followed by 1 $\mu \mathrm{g} / \mathrm{kg}$ infused over a 6-hour period), and those assigned to the placebo group received an identical volume of normal saline solution. There were no other differences in perioperative treatment, and all staff involved in the care of the subjects were blinded to subject assignment.

Outcome variables included perioperative hemodynamic data, pressor and inotropic requirements, morbidity, and mortality. Morbidity parameters included the prevalence of atrial fibrillation, pacemaker dependence, myocardial ischemia and infarction, and mechanical assistance (intra-aortic balloon pump or left ventricular assist device). Pharmacologic and hemodynamic data were collected before induction of anesthesia, on weaning from cardiopulmonary bypass, on arrival in the intensive care unit (ICU), and at frequent subsequent intervals until discharge from the ICU. Perioperative myocardial ischemia/infarction was diagnosed electrocardiographically by an independent cardiologist, blinded to the protocol, who applied creatine kinase $\mathrm{MB}$ fraction $(>6 \%)$, aspartate aminotransferase $(>100 \mathrm{mg} / \mathrm{dL})$, and electrocardiographic criteria for myocardial infarction.

Preoperative and anesthetic management. Patients receiving $\beta$-blockers or calcium channel blockers (or both) received these medications on the morning of the operation. Only patients who had been receiving stable dosages of these medications for at least 2 weeks before the operation were included in the study. Preoperative medication consisted of midazolam 0.05 to $0.1 \mathrm{mg} / \mathrm{kg}$ orally in the preoperative holding area 1 hour before the operation. On arrival in the operative suite and before the induction of anesthesia, routine monitoring was established, including placement of topical electrocardiographic electrodes, radial artery and thermodilution catheters (Swan-Ganz catheters; Baxter Healthcare Corp, Edwards Division, Santa Ana, Calif), and digital pulse oximetry. Hemodynamic monitoring included continuous measurement of heart rate, arterial and central venous pressure, cardiac output, and pulmonary artery pressure. Intravenous induction was effected with fentanyl $(25 \mu \mathrm{g} / \mathrm{kg})$, midazolam $(0.05 \mathrm{mg} / \mathrm{kg})$, and vecuronium $(0.1 \mathrm{mg} / \mathrm{kg})$. Inhalational anesthetics were not used. Anesthesia was maintained with a combination of intravenous fentanyl, midazolam, and vecuronium by continuous infusion. Operating room data were continuously recorded by the LifeLog automated record keeper (Modular Instruments, Malvern, Pa) and stored in a database located in a central file server. Data from the ICU and cardiac step-down units were collected on a portable computer and analysis was performed off-line.

Statistical analysis. All data were analyzed with the use of SAS system software (SAS Institute, Inc, Cary, NC). Data were presented as mean \pm standard deviation. Preliminarily, continuous variables were compared by the paired and unpaired Student $t$ test and analysis of variance (ANOVA), and discrete variables were analyzed by $\chi^{2}$ and Fisher's exact test. ${ }^{10-12}$

To discern whether a treatment effect existed postoperatively (myocardial ischemia/infarction, pacemaker dependence, and atrial fibrillation), we used multiple logistic regression, controlling for other preoperative and demographic variables, such as age, gender, ejection fraction, and calcium channel and $\beta$-blockade. These equations also generate odds ratios and $95 \%$ confidence intervals. The longitudinal data, such as heart rate, cardiac index, systemic vascular resistance, and dopamine and dobutamine administration, were studied with the use of a number of statistical methods: repeated-measures ANOVA (Proc Mixed) to discern group differences over time and Generalized Estimation Equations (the GEE method) for incorporating covariates into the model. Both methods allow for the covariance structure of the data to be estimated, due to the potential correlation among observations on the same individual between time points.

\section{Results}

Patient demographics. A total of 177 patients were enrolled and randomized in the study. Two patients were removed from the study at the discretion of the attending cardiologist and 1 patient was excluded because of massive hemorrhage in the immediate postoperative period. Four patients were excluded on the basis of incomplete data collection. In the final analyzed cohort of 170 patients, 81 were randomized to the $\mathrm{T}_{3}$ group and 89 were assigned to the placebo group. As summarized in Table I, the 2 groups were statistically equivalent with respect to a variety of preoperative and intraoperative factors, including medical and smoking history, left ventricular ejection fraction, preoperative medications, initial intraoperative hemodynamics, and duration of cardiopulmonary bypass and aortic crossclamping. However, despite adequate randomization with respect to these factors, patients in the placebo group were an average of 4 years older than the patients in the $\mathrm{T}_{3}$ group. Therefore, for all statistical analyses, 
Table I. Patient demographics

\begin{tabular}{|c|c|c|c|c|}
\hline Variable & All patients & $T_{3}$ group & Placebo group & $\mathrm{P}$ value \\
\hline $\mathrm{n}$ & 170 & 81 & 89 & \\
\hline Age (y) & $64.1 \pm 11.5$ & $62.1 \pm 12.5$ & $66.0 \pm 10.8$ & .03 \\
\hline Male & $139(81.2 \%)$ & $65(80.2 \%)$ & $74(83.1 \%)$ & .77 \\
\hline \multicolumn{5}{|l|}{ Preoperative characteristics } \\
\hline Cigarettes & $100(58.1 \%)$ & $49(60.5 \%)$ & $51(57.3 \%)$ & .79 \\
\hline Hypertension & $97(56.4 \%)$ & $49(60.5 \%)$ & $48(53.9 \%)$ & .48 \\
\hline Preoperative MI & $81(47.1 \%)$ & $36(44.4 \%)$ & $45(50.6 \%)$ & .52 \\
\hline$\beta$-Blockers & $120(69.8 \%)$ & $54(66.7 \%)$ & $66(74.2 \%)$ & .37 \\
\hline Calcium channel blockers & $58(33.7 \%)$ & $29(35.8 \%)$ & $29(32.6 \%)$ & .78 \\
\hline LV ejection fraction $(\%)$ & $39.5 \pm 13.2$ & $39.2 \pm 16.9$ & $39.7 \pm 15.9$ & .84 \\
\hline \multicolumn{5}{|l|}{ Intraoperative characteristics } \\
\hline CPB time (min) & $103.9 \pm 27.9$ & $105.8 \pm 28.5$ & $102.1 \pm 27.4$ & .39 \\
\hline Aortic crossclamp time (min) & $69.0 \pm 21.3$ & $69.0 \pm 23.2$ & $69.0 \pm 22.9$ & 1.00 \\
\hline Induction HR & $64 \pm 13$ & $63 \pm 16$ & $65 \pm 15$ & .40 \\
\hline Induction CI & $2.37 \pm 0.64$ & $2.43 \pm 0.65$ & $2.30 \pm 0.63$ & .19 \\
\hline Induction PAD & $15 \pm 6$ & $15 \pm 9$ & $16 \pm 6$ & .39 \\
\hline Induction SVR & $1605 \pm 513$ & $1567 \pm 599$ & $1645 \pm 553$ & .38 \\
\hline
\end{tabular}

$M I$, Myocardial infarction; $L V$, left ventricular; $C P B$, cardiopulmonary bypass; $H R$, heart rate; $C I$, cardiac index; $P A D$, pulmonary artery diastolic; $S V R$, systemic vascular resistance.

Table II. Hemodynamic responses to $T_{3}$ and placebo

\begin{tabular}{|c|c|c|c|c|c|c|}
\hline \multirow[b]{2}{*}{ Time point } & \multicolumn{2}{|c|}{ Heart rate } & \multicolumn{2}{|c|}{ Cardiac index } & \multicolumn{2}{|c|}{ Systemic vascular resistance } \\
\hline & $T_{3}$ & Placebo & $T_{3}$ & Placebo & $T_{3}$ & Placebo \\
\hline Before induction & $63 \pm 11$ & $65 \pm 14$ & $2.43 \pm 0.65$ & $2.33 \pm 0.58$ & $1567 \pm 472$ & $1671 \pm 517$ \\
\hline After CPB & $72 \pm 14$ & $76 \pm 17$ & $2.55 \pm 0.57$ & $2.16 \pm 0.52$ & $1139 \pm 417$ & $1458 \pm 533$ \\
\hline ICU arrival & $76 \pm 16$ & $77 \pm 17$ & $2.27 \pm 0.68$ & $2.20 \pm 0.65$ & $1584 \pm 638$ & $1623 \pm 677$ \\
\hline Six hours & $89 \pm 17$ & $88 \pm 18$ & $2.91 \pm 0.65$ & $2.63 \pm 0.63$ & $1069 \pm 362$ & $1129 \pm 337$ \\
\hline Twelve hours & $90 \pm 15$ & $85 \pm 15$ & $3.01 \pm 0.58$ & $2.80 \pm 0.64$ & $1006 \pm 345$ & $1082 \pm 273$ \\
\hline$P$ value* & \multicolumn{2}{|c|}{.69} & \multicolumn{2}{|c|}{.0001} & \multicolumn{2}{|c|}{.21} \\
\hline
\end{tabular}

$C P B$, Cardiopulmonary bypass; $I C U$, intensive care unit.

*Multivariable longitudinal testing by repeated measures analysis (Generalized Estimating Equation, GEE) after adjusting for age and other covariates.

age was adjusted for by multivariable techniques.

Hemodynamic effects. Before induction of anesthesia, the $\mathrm{T}_{3}$ and placebo groups were similar with respect to major hemodynamic indices, including heart rate, cardiac index, pulmonary artery pressure, and systemic vascular resistance. These parameters were evaluated subsequently after cardiopulmonary bypass, on arrival in the ICU, and 6 and 12 hours after admission to the ICU. By multivariable longitudinal analysis, patients in the $T_{3}$ group demonstrated a significantly higher cardiac index than patients in the placebo group in the 12 hours after cardiopulmonary bypass, with no differences in heart rate, systemic vascular resistance, or pulmonary artery pressure between groups in the postoperative period (Table II).

Inotropic requirements. Postoperatively, requirements for inotropic support were recorded for 48 hours. In the placebo group, $18 \%$ of patients were treated with dopamine and 9\% were receiving dobutamine on arrival in the ICU, whereas only $11 \%$ and $5 \%$, respectively, of the patients in the $\mathrm{T}_{3}$ group were receiving these agents. Inotropic requirements remained lower in the $T_{3}$ group than in the placebo group at all subsequent time points, with significantly less dopamine dependence $(P=.04)$ and a trend toward less dobutamine dependence $(P=$ $.07)$ by univariate longitudinal data analysis. Multivariate analysis of these data identified a number of independent factors with influence on inotropic requirements, including age $(P=.04$ for dopamine and $P=$ .0001 for dobutamine), ejection fraction $(P=.0007$ for dobutamine), and preoperative use of calcium channel-blocking agents ( $P=.02$ for dopamine). After correcting for these factors, patients in the $\mathrm{T}_{3}$ group had a significantly decreased prevalence of dopamine administration $(P=.01)$ but no significant differences in dobutamine administration $(P=.43)$ (Table III). 
Table III. Postoperative inotropic administration in $T_{3}$ and placebo groups

\begin{tabular}{lrrrrr}
\hline & \multicolumn{2}{c}{ Dopamine } & & \multicolumn{2}{c}{ Dobutamine } \\
\cline { 2 - 3 } \cline { 5 - 6 } Time point & $T_{3}$ & Placebo & & $T_{3}$ & Placebo \\
\hline ICU arrival & 11.1 & 18.0 & & 4.9 & 9.0 \\
Six hours & 7.4 & 18.0 & & 6.2 & 14.6 \\
Twelve hours & 11.1 & 19.1 & & 6.2 & 14.6 \\
Twenty-four hours & 4.9 & 15.7 & & 3.7 & 11.2 \\
$P$ value* & .01 & & & .43 & \\
\hline
\end{tabular}

Values represent percentage of patients who received inotropic support.

*Using multivariable logistic regression/repeated-measures ANOVA.

Clinical outcome measures (morbidity and mortality). Overall and group-specific morbidity and mortality are detailed in Table IV. Overall, 19 patients (11\%) demonstrated evidence of perioperative myocardial ischemia, and 11 of these $(6.5 \%)$ met criteria for myocardial infarction ( 8 transmural, 3 subendocardial). Twenty-one patients (12\%) had atrial fibrillation. Independent predictors of myocardial ischemia included preoperative calcium channel blocker therapy, increasing cardiopulmonary bypass time, and randomization to the placebo group (Table V). Patients in the $\mathrm{T}_{3}$ group had a $4 \%$ prevalence of myocardial ischemia, which was significantly lower than the $18 \%$ noted in the placebo group $(P=.0019)$. Although the small number of infarctions did not allow attainment of statistical significance, the rate of this complication was $2.5 \%$ in the $\mathrm{T}_{3}$ group as compared with $10.1 \%$ in the placebo group. Atrial fibrillation was as frequent in the $\mathrm{T}_{3}$ group (12.3\%) as in the placebo group (12.4\%), but the prevalence of this complication increased with age and was significantly lower in patients receiving $\beta$ blocker therapy (Table V). Temporary or permanent pacemaker support was required in a greater proportion of patients in the placebo group $(24.7 \%)$ than in the $\mathrm{T}_{3}$ group (13.6\%, $P=.013)$ and was also more common with increasing age and cardiopulmonary bypass time (Table V). Furthermore, 7 patients $(4.1 \%)$ in the placebo group required temporary mechanical assistance after the operation (4 intra-aortic balloon pumps, 3 left ventricular assist devices), whereas no patient in the $\mathrm{T}_{3}$ group required such assistance. Finally, there were 2 deaths in the entire cohort of patients, both occurring in patients assigned to the placebo group.

Influence of preoperative $\beta$-blocker therapy. The effect of $\mathrm{T}_{3}$ administration on perioperative cardiac index was most apparent in patients receiving $\beta$-blocker agents before the operation. In these patients, $\mathrm{T}_{3}$ resulted in a progressive increase in cardiac index
Table IV. Postoperative morbidity and mortality in $T_{3}$ and placebo groups

\begin{tabular}{lccc}
\hline & $T_{3}$ & Placebo & P value $^{*}$ \\
\hline Myocardial ischemia & $3(3.7 \%)$ & $16(18.0 \%)$ & .0019 \\
Myocardial infarction & $2(2.5 \%)$ & $9(10.1 \%)$ & .06 \\
Atrial fibrillation & $10(12.3 \%)$ & $11(12.4 \%)$ & 1.00 \\
Pacemaker dependence & $11(13.6 \%)$ & $22(24.7 \%)$ & .0128 \\
Mechanical assistance & $0(0 \%)$ & $7(7.9 \%)$ & .01 \\
IABP & $0(0 \%)$ & $4(4.5 \%)$ & \\
LVAD & $0(0 \%)$ & $3(3.4 \%)$ & \\
Death & $0(0 \%)$ & $2(2.2 \%)$ & .23
\end{tabular}

$I A B P$, Intra-aortic balloon pump; $L V A D$, left ventricular assist device. *By multiple logistic regression, adjusting for other covariates.

beginning after cardiopulmonary bypass through 12 hours after ICU admission (Table VI). Systemic vascular resistance was similarly reduced after bypass in patients receiving $\mathrm{T}_{3}$ as compared with those in the placebo incidence cohort. Overall, $\beta$-blockade was associated with a slightly lower prevalence of dopamine and dobutamine administration. However, within this group, $\mathrm{T}_{3}$ administration further lowered inotropic use at all postoperative time points. Finally, the overall incidence of perioperative myocardial ischemia (11\%) and the reduction in this incidence associated with $\mathrm{T}_{3}$ administration were no different in patients receiving $\beta$-blockers than in the overall patient cohort. As noted earlier, patients receiving preoperative $\beta$-blocking agents had a significantly lower prevalence of atrial fibrillation, with no difference between those in the $T_{3}$ and placebo groups.

Effects of gender. Notably, the afore-described beneficial effects of $\mathrm{T}_{3}$ on perioperative hemodynamics were not observed in the female cohort of patients, in whom there was no significant improvement in cardiac index after $\mathrm{T}_{3}$ administration (Table VII). In fact, multivariate analysis revealed male gender as an independent predictor of improved postoperative cardiac index (data not shown). Nonetheless, the decrease in inotropic administration in women receiving $\mathrm{T}_{3}$ was of similar magnitude to that of the total $\mathrm{T}_{3}$ cohort. Women receiving $\mathrm{T}_{3}$ also had a substantial reduction in incidence of myocardial ischemia when compared with women assigned to the placebo group.

\section{Discussion}

For more than a decade, the cardiovascular effects of thyroid hormone have been investigated both in the laboratory and in clinical trials. Initial results in rodent models of myocardial infarction and heart failure suggested that administration of physiologic doses of $\mathrm{T}_{3}$ produced significant improvement in left ventricular 
Table V. Independent predictors of myocardial ischemia, atrial fibrillation, and pacemaker dependence*

\begin{tabular}{lllll}
\hline Outcome variable & \multicolumn{1}{c}{ Preoperative variable } & P value & Odds ratio & $95 \%$ CI \\
\hline Myocardial ischemia & $\mathrm{T}_{3}$ group & .0019 & 0.11 & $0.03-0.45$ \\
& Calcium channel blocker therapy & .0129 & 3.88 & $1.33-11.29$ \\
& CPB time (per 30 minutes) & .0292 & 1.87 & $1.07-3.29$ \\
Atrial fibrillation & Age (per decade) & .0046 & 2.14 & $1.26-3.61$ \\
& B-Blocker therapy & .0095 & 0.28 & $0.10-0.73$ \\
Pacemaker dependence & $\mathrm{T}_{3}$ group & .0128 & 0.35 & $0.16-0.80$ \\
& Age (per decade) & .0431 & 1.48 & $1.01-2.18$ \\
& CPB time (per 30 minutes) & .0303 & 1.59 & $1.04-2.43$ \\
\hline
\end{tabular}

$C I$, Confidence interval; $C P B$, cardiopulmonary bypass.

*By multivariable logistic regression analysis.

Table VI. Results in patients on preoperative $\beta$-blocker therapy

\begin{tabular}{lccc}
\hline & $T_{3}$ & Placebo & P value* \\
\hline $\mathrm{n}$ & 53 & 66 & \\
Cardiac index $\left(\mathrm{L} / \mathrm{min} / \mathrm{m}^{2}\right)$ & & & .0088 \\
$\quad$ Induction & $2.4 \pm 0.6$ & $2.3 \pm 0.5$ & \\
$\quad$ After CPB & $2.6 \pm 0.6$ & $2.1 \pm 0.5$ & \\
$\quad$ Six hours & $2.9 \pm 0.6$ & $2.6 \pm 0.6$ & \\
$\quad$ Twelve hours & $3.1 \pm 0.6$ & $2.8 \pm 0.7$ & \\
Dopamine dependence (\%) & & & .0498 \\
$\quad$ ICU arrival & 9.3 & 16.7 & \\
$\quad$ Six hours & 3.7 & 15.2 & \\
$\quad$ Twelve hours & 9.3 & 13.6 & \\
$\quad$ Twenty-four hours & 3.7 & 12.1 & \\
Myocardial ischemia $(\%)$ & 3.7 & 16.7 & .036 \\
Atrial fibrillation $(\%)$ & 5.6 & 9.1 & .512 \\
\hline
\end{tabular}

$C P B$, Cardiopulmonary bypass; $I C U$, Intensive care unit.

*Multivariable longitudinal testing by Generalized Estimating Equation (GEE) after adjusting for age and other covariates.

performance. ${ }^{13-15}$ Concurrently, Novitzky and colleagues ${ }^{16}$ reported that $T_{3}$ exerted significant beneficial effects when administered to pigs subjected to myocardial ischemia and cardiopulmonary bypass. In subsequent years, other basic science and clinical investigations supported the premise that thyroid hormone metabolism was altered in advanced heart failure and that $\mathrm{T}_{3}$ administration improved myocardial performance after cardioplegic arrest and ischemic injury. ${ }^{17-19}$ In one clinical study, $\mathrm{T}_{3}$ was found to decrease the prevalence of atrial fibrillation after CABG surgery. ${ }^{22}$ Despite these encouraging results, other studies have failed to demonstrate significant improvements in clinical outcome indices in patients treated with $\mathrm{T}_{3}{ }^{21,22}$ For this reason, $\mathrm{T}_{3}$ has not become a routine component of pharmacologic management of patients with heart failure or those undergoing cardiopulmonary bypass. In an effort to reconcile the issues raised by these conflicting reports, we performed a clinical trial designed to close-
Table VII. Results in female patients

\begin{tabular}{lccc}
\hline & $T_{3}$ & Placebo & P value* \\
\hline $\mathrm{n}$ & 17 & 14 & \\
Cardiac index $\left(\mathrm{L} / \mathrm{min} / \mathrm{m}^{2}\right)$ & & & .0001 \\
$\quad$ Induction & $2.1 \pm 0.6$ & $2.4 \pm 0.8$ & \\
$\quad$ After CPB & $2.2 \pm 0.6$ & $2.1 \pm 0.5$ & \\
$\quad$ Six hours & $2.3 \pm 0.4$ & $2.7 \pm 0.7$ & \\
$\quad$ Twelve hours & $2.7 \pm 0.5$ & $2.6 \pm 0.5$ & \\
Dopamine dependence (\%) & & & .42 \\
$\quad$ ICU arrival & 11.8 & 21.4 & \\
Six hours & 11.8 & 28.6 & \\
$\quad$ Twelve hours & 17.6 & 35.7 & \\
$\quad$ Twenty-four hours & 11.8 & 28.6 & \\
Myocardial ischemia (\%) & 0.0 & 21.4 & .07 \\
Atrial fibrillation (\%) & 11.1 & 21.4 & .631 \\
\hline
\end{tabular}

$C P B$, Cardiopulmonary bypass; $I C U$, intensive care unit. *Multivariable longitudinal testing by Generalized Estimating Equation (GEE) after adjusting for age and other covariates.

ly examine the effect of $\mathrm{T}_{3}$ on both physiologic parameters and clinically relevant outcome variables in patients undergoing $\mathrm{CABG}$.

In our study, patients receiving $\mathrm{T}_{3}$ on crossclamp removal and for 6 subsequent hours demonstrated significantly better myocardial function after the operation than patients receiving placebo, resulting in lesser requirements for inotropic support. Interestingly, these benefits were not diminished by preoperative $\beta$-blocker therapy. Although preoperative $\beta$-blocker therapy did not influence the overall prevalence of perioperative myocardial ischemia, $\mathrm{T}_{3}$ administration dramatically reduced the rate of this complication. This effect on the prevalence of perioperative ischemia is consistent with data obtained in animal models of myocardial ischemia. The requirement for mechanical assistance, an indicator of profound myocardial dysfunction, was significantly reduced in patients receiving $\mathrm{T}_{3}$, underscoring the potential clinical utility of this agent. 
Notably, although the clinically relevant beneficial effects of $\mathrm{T}_{3}$ administration on perioperative inotropic support and myocardial infarction were experienced by patients of both sexes, improvements in cardiac index were not observed in women. An explanation for the differences between the genders remains to be found.

Atrial fibrillation remains a common postoperative complication in patients undergoing CABG surgery, occurring in $5 \%$ to $40 \%$ of patients and contributing significantly to length of hospital stay and costs. ${ }^{23} \mathrm{~A}$ variety of factors have been identified as predictors of perioperative atrial fibrillation: These include advanced age, male gender, preoperative hypertension, the requirement for intra-aortic balloon pump support, postoperative pneumonia, and the need for extended postoperative ventilatory support. ${ }^{24-26}$ Others have suggested that the presence of significant disease in the vessels supplying the sinoatrial and atrioventricular nodes is a strong predictor of postoperative atrial arrhythmias. ${ }^{27}$ In our study, although increased age conferred a higher risk for postoperative atrial fibrillation, neither gender, cardiopulmonary bypass time, nor $\mathrm{T}_{3}$ therapy appeared to affect the incidence of this arrhythmia. Finally, in patients receiving $\mathrm{T}_{3}$, there was a dramatic decrease in the need for postoperative pacemaker support (13.6\% vs $24.7 \%$ ) during the first 48 hours after cardiopulmonary bypass, confirming clinically the experimentally established chronotropic effects of this agent. Of the 6 patients who eventually required permanent pacemaker insertion, only 1 was a member of the $\mathrm{T}_{3}$ group.

In conclusion, our single-center study has confirmed the positive inotropic and chronotropic effects of $T_{3}$ administered perioperatively in patients undergoing CABG and has furthermore identified clinically relevant benefits in these patients, including reduced rates of myocardial ischemia, pacemaker dependence, and mechanical assistance. Although female patients did not have the same improvement in hemodynamic indices after $\mathrm{T}_{3}$ administration as their male counterparts, they experienced similar reductions in postoperative inotropic requirements and complication rates. The mechanisms by which $T_{3}$ exerts these beneficial effects is currently a matter of speculation and warrants a multicenter investigation to confirm that $\mathrm{T}_{3}$ treatment reduces perioperative myocardial infarction, lessens the need for mechanical support, and increases survival.

\section{REFERENCES}

1. Klein I. Thyroid hormone and the cardiovascular system. Am J Med 1990;88:631-7.

2. Morkin E, Flink IL, Goldman S. Biochemical and physiologic effects of thyroid hormone on cardiac performance. Prog Cardiovasc Dis 1983;25:435-63.

3. Suko J. Alterations of $\mathrm{Ca} 2+$ uptake and $\mathrm{Ca} 2+$ activated ATPase of cardiac sarcoplasmic reticulum in hyper- and hypothyroidism. Biochim Biophys Acta 1971;252:324-7.

4. Mercadier JJ, Lompre AM, Wisnewsky C, et al. Myosin isoenzymic changes in several models of rat cardiac hypertrophy. Circ Res 1981;49:525-32.

5. Holland FW, Brown PS, Weintraub BD, Clark RE. Cardiopulmonary bypass and thyroid function: a "euthyroid sick syndrome." Ann Thorac Surg 1991;52:46-50.

6. Robuschi G, Medici D, Fesani F, et al. Cardiopulmonary bypass: a low $\mathrm{T}_{3}$ and $\mathrm{T}_{4}$ syndrome with blunted thyrotropin (TSH) response to thyrotropin-releasing hormone (TRH). Hormone Res 1986;23:151-8.

7. Novitzky MD, Cooper DC, Barton CI, et al. Triiodothyronine as an inotropic agent after open-heart surgery. J Thorac Cardiovasc Surg 1989;98:972-8.

8. Novitzky MD, Cooper DC, Human PA, Reichart B, Zuhdi N. Triiodothyronine therapy for heart donor and recipient. J Heart Transplant 1988;7:370-6.

9. Bennett-Guerrero E, Jimenez JL, White WD, et al. Cardiovascular effects of intravenous triiodothyronine in patients undergoing coronary artery bypass graft surgery. JAMA 1996;275:68792.

10. Statistics in medicine. Colton T. Boston: Little Brown.

11. Principles of biostatistics. Ragano M, Gauvreau K. Belmont [CA]: Duxbury Press.

12. Statistical methods for rates and proportions. Fleiss JL. ed 2. New York: John Wiley; 1983.

13. Gay RG, Graham S, Aguirre M, Goldman S, Morkin E. Effects of 10-12 day treatment with L-thyroxine in rats with myocardial infarction. Am J Physiol 1988;255:H801-6.

14. Gay R, Gustafson TA, Goldman S, Morkin E. Effects of L-thyroxine in rats with chronic heart failure after myocardial infarction. Am J Physiol 1987;253:H341-6.

15. Dyke CM, Yeh T, Lehman JD, et al. Triiodothyronine-enhanced left ventricular function after ischemic injury. Ann Thorac Surg 1991;52:14-9.

16. Novitzky D, Human PA, Cooper DK. Inotropic effect of triiodothyronine following myocardial ischemia and cardiopulmonary bypass: an experimental study in pigs. Ann Thorac Surg 1988;45:50-5.

17. Hamilton MA, Stevenson LW, Luu M, et al. Altered thyroid metabolism in advanced heart failure. J Am Coll Cardiol 1990; 16:91-5.

18. Klemperer JD, Zelano J, Helm RE, et al. Triiodothyronine improves left ventricular function without oxygen wasting effects after global hypothermic ischemia. J Thorac Cardiovasc Surg 1995; 109:457-65.

19. Walker JD, Crawford FA, Spinale FG. 3,5,3’ Triiodo-L-thyronine pretreatment with cardioplegic arrest and chronic left ventricular dysfunction. Ann Thorac Surg 1995;60:292-9.

20. Klemperer JD, Klein IL, Ojamaa K, et al. Triiodothyronine therapy lowers the incidence of atrial fibrillation after cardiac operations. Ann Thorac Surg 1996;61:1323-9.

21. Klemperer JD, Klein IL, Gomez M, et al. Thyroid hormone treatment after coronary artery bypass surgery. N Engl J Med 1995; 333:1522-63.

22. Bennet-Guerrero E, Jimenez JL, White WD, et al. Cardiovascular 
effects of intravenous triiodothyronine in patients undergoing coronary artery bypass graft surgery. JAMA 1996;275:687-92.

23. Kolvekar S, D'Souza A, Akhatar P, et al. Role of atrial ischemia in development of atrial fibrillation following coronary artery bypass surgery. Eur J Cardiothoracic Surg 1997;11:70-5.

24. Mathew JP, Parks R, Savino JS, et al. Atrial fibrillation following coronary artery bypass surgery: predictors, outcomes, and resource utilization. JAMA 1996;276:300-6.

25. Aranki SF, Shaw DP, Adams DH, et al. Predictors of atrial fibrillation after coronary artery surgery: current trends and impact on hospital resources. Circulation 1996;94:390-7.

26. Butler J, Chong JL, Rocker GM, Pillai R, Westaby S. Atrial fibrillation after coronary artery bypass grafting: a comparison of cardioplegia versus intermittent aortic cross-clamping. Eur J Cardiothoracic Surg 1993;7:23-5.

27. Mendes LA, Connelly GP, McKenney P, et al. Right coronary artery stenosis: an independent predictor of atrial fibrillation after coronary artery bypass surgery. J Am Coll Cardiol 1995;25:198-202.

\section{Discussion}

Dr Andrew S. Wechsler (Philadelphia, Pa) [comments read by Dr Hartzell V. Schaff, Rochester, Minn]. Dr Wechsler was unable to be here, but he did record his review of the manuscript. His comments are as follows:

Decreased levels of serum $T_{3}$ have been consistently demonstrated after cardiopulmonary bypass. Depression of $\mathrm{T}_{3}$ levels exceeds that predicted from hemodilution and cardiopulmonary bypass and is added to the list of interventions possibly associated with euthyroid-sick syndrome.

Far more controversial is the question of whether restoring the serum $\mathrm{T}_{3}$ levels to normal results in a hemodynamic advantage. Novitzky and his colleagues have consistently demonstrated an improved hemodynamic performance after $\mathrm{T}_{3}$ administration, but a Duke study of 211 patients showed minimal effects. Klemper studied $\mathrm{T}_{3}$ administration compared with placebo in 142 patients and found mild hemodynamic improvement but no change in important clinical outcomes. Your study demonstrates a major hemodynamic and survival effect. The effect is much stronger than those previously demonstrated and raises some interesting questions. Dr Wechsler has 4 questions to which I will add 2.

1. Do you believe that the dose of $1 \mu \mathrm{g} / \mathrm{kg}$ as a bolus and then over the next 6 hours differed significantly enough from doses used in prior studies to account for your observations?

2. Did you require specific objective hemodynamic indices to be obtained before initiating the drug? Could the vasodilator effect of $\mathrm{T}_{3}$ and the accompanying increased inotropic therapy have increased the cardiac index to account for the differences?

3. Your statistical method used predominantly univariate comparisons between significant end points. Do you think the data would hold up if subjected to a logistic regression analysis or multivariate analysis that would eliminate data points that served as surrogates for one or another?

4. I did not note in your table whether there was a significant difference in patients being operated on under reoperative conditions between the 2 groups. Was there a difference?
I would like to add 2 questions to Dr Wechsler's:

One point that stood out in your presentation was the large difference in enzyme leak. Was there a difference in Q-wave myocardial infarction between the 2 groups? If not, how do you account for postoperative creatine kinase release? As I understand your protocol, the drug is given after the crossclamp is removed. Do you hypothesize some protective effect, perhaps an influence on reperfusion, that decreases ischemic injury?

Dr Mullis-Jansson. To answer the first question in relationship to the dosage of the $T_{3}$ : dosages that had been given in the past ranged from approximately $0.4 \mu \mathrm{g} / \mathrm{kg}$ all the way up to 2 to $3 \mu \mathrm{g} / \mathrm{kg}$, given as a bolus. In the groups that had the 2 - to $3-\mu \mathrm{g} / \mathrm{kg}$ boluses, there were difficulties in terms of maintaining pressure in relationship to vasodilatory responses. Klemper's group used a $0.8-\mu \mathrm{g} / \mathrm{kg}$ bolus. I do not think the $0.2-\mu \mathrm{g} / \mathrm{kg}$ difference between our study and Klemper's study would account for the difference in the results of the study. One explanation for the difference in the result may be in relationship to the percentage of patients in Klemper's study who had preoperative left ventricular dysfunction. We had a higher percentage of patients with ejection fractions less than $40 \%$ than did Klemper. About $45 \%$ of our patients had an ejection fraction less than $40 \%$, and that may indeed explain that there may be a selective beneficial effect in patients with more morbid preoperative left ventricular function than the patients with normal left ventricular function.

Dr Schaff. The second question was whether the differences in hemodynamics might be accounted for by vasodilatation caused by the $T_{3}$ and in subsequent inotropic use to make up for that decrease in peripheral vascular resistance.

Dr Mullis-Jansson. We certainly did not see that. In fact, the only end point in which we saw a statistical difference in systemic vascular resistance was at the immediate postpulmonary/cardiopulmonary bypass measurement. In all subsequent measurements there was no difference between the groups, so I do not believe this is an afterload-reducing effect.

Dr Schaff. What about the difference in creatine kinase release? Is there a myocardial protective effect when the drug is given after the crossclamp release?

Dr Mullis-Jansson. I cannot explain it. The diagnosis of myocardial infarction was made by a cardiologist who was blinded to the protocol. The cardiologist was given the data in terms of each of the patients, and that included 5 days of electrocardiograms and all the enzyme data that were obtained on the patients for 3 days after the operation. The diagnosis was made on that basis.

Dr Karl H. Krieger (New York, NY). One further question. Atrial fibrillation is a major problem after CABG surgery, particularly when considering length of stay. Dr Klemper's study noted a statistically significant decrease in atrial fibrillation; his rate, I think, was cut in half in patients who received $\mathrm{T}_{3}$. In your study you showed a decreased incidence, corroborating his study, but the difference did not reach statistical significance. Can you propose a mechanism by which $\mathrm{T}_{3}$ would affect atrial fibrillation in the postoperative period? 
Dr Mullis-Jansson. In the animal model the beneficial effects seem to be in relationship to decreasing the effects of ischemia on sinoatrial and atrioventricular node function. In the past, one of the proposed mechanisms for atrial fibrillation after CABG surgery has been to cause an insult to the sinoatrial or atrioventricular node. Perhaps $\mathrm{T}_{3}$ in some way protects this nodal mechanism such that the incidence of postoperative arrhythmias will be lower.

Dr Ahmad Rajaii Khorasan (Neptune, NJ). The dramatic difference in your survival results and the need for left ventricular assist devices in the 2 groups raises a question about the other important factors that can influence these outcomes: for example, the extent of coronary disease, pump time, number of CABGs, and so on. Please comment on the distribution of these variables in the 2 groups.

Dr Mullis-Jansson. In terms of those demographic parameters, the groups were equivalent. There was no difference in the ischemic crossclamp time or cardiopulmonary bypass time or in the number of grafts that were done. The patients seemed to be equivalent in the 2 groups. We could find no difference. In fact, other papers have suggested that some of the differences may be in relationship to those parameters, such as preoperative incidence of hypertension or advanced age (age is certainly a predictor of increased morbidity and mortality). Our groups, however, were equivalent.
Dr Patrick L. Ergina (Montreal, Quebec, Canada). I have a question that was alluded to initially. I noticed that you wanted to keep the mean arterial pressures fairly high. When you treated those patients with pressors, which many people believe have an inotropic effect to combat the effect seen on your slide of decreased systemic vascular resistance on the $\mathrm{T}_{3}$ group, did you look at that specifically as a possible confounding variable? You used norepinephrine bitartrate (Levophed), but you did not document its use.

Dr Mullis-Jansson. Right. We do use norepinephrine bitartrate (Levophed), although that is not shown in our illustrations. The dosages of norepinephrine bitartrate (Levophed) between the 2 groups were equivalent.

Dr Ergina. My second question concerns pacing. Pacing was more prevalent in the placebo group, and you noted that there were more ischemic changes in 1 group. How did you approach the paced electrocardiograms?

Dr Mullis-Jansson. In this study there was only 1 patient who was asystolic and in whom we could not get any type of rhythm strip. In the other patients, the temporary pacemaker was turned off before the 12-lead electrocardiogram was performed, and then the cardiologist read the 12-lead electrocardiogram with the patient's own native rhythm, albeit a slow one. He read it from that rhythm and rate. 